\title{
Avoiding reputation damage in financial restatements
}

by Fred H. M. Gertsen, Cees B. M. van Riel and Guido Berens

\section{If your company is forced to issue a financial restatement, how can the right managerial behaviour help to minimise the damage to corporate reputation?}

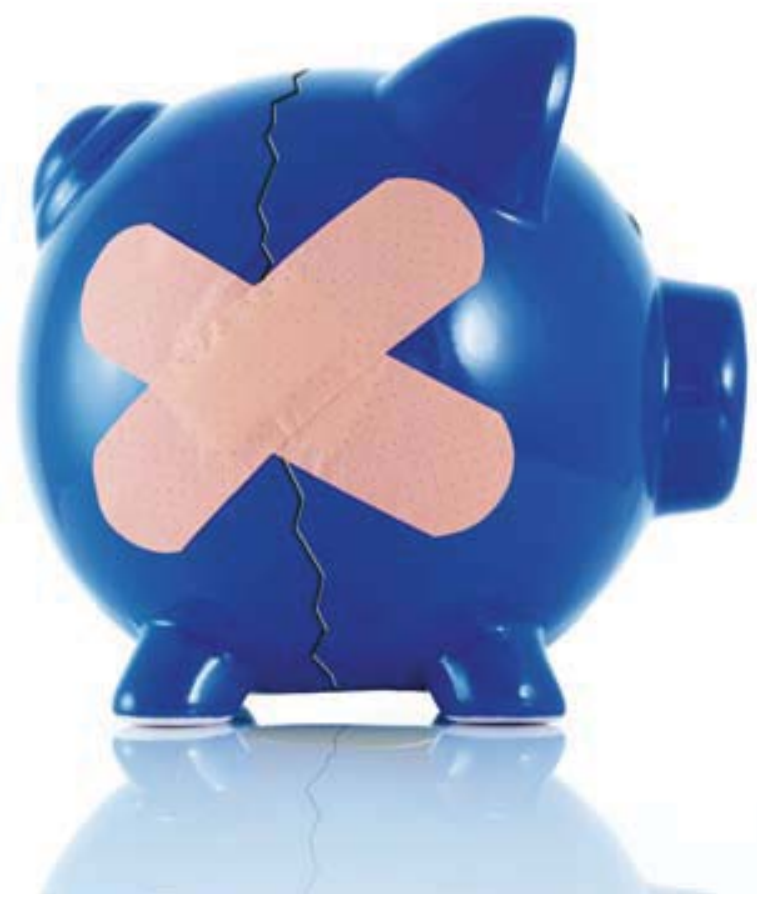

Do we trust our public companies to always behave honourably and above board, when it comes to presenting their figures? The answer is debatable. First Enron, then Worldcom, and thereafter a succession of other highprofile accounting scandals have generated negative headlines in the international press and taken their toll on investor confidence and public trust.

In most countries, corporate governance and accounting requirements have become more stringent post-Enron. Demands for greater transparency mean that companies are legally obliged to issue financial restatements if their accounts differ from those previously presented, for example in annual reports.

Market and press reactions to such revisions are, predictably, negative, and most who have issued financial restatements have faced serious problems - substantial financial losses and falls in share price, replacement of their full Board of Directors, and, in the worst cases, even bankruptcy.

Yet not all restatements need have such devastating effects, argue researchers from RSM. Findings from their major study of financial restatement cases, involving leading US and European companies, suggest that companies can manage such crises judiciously so as to minimise or limit the damage to reputation and future financial performance.

The research team - Fred Gertsen of PriceWaterhouseCoopers, and Professors Cees van Riel and Guido Berens of RSM's Centre for Corporate Communication - saw opportunities for generating better understanding not only of what triggers the need for financial restatements and determines their severity but, more critically, how to handle them most effectively, should the need arise.

The goal of our research was to define such guidelines, by providing insight into the managerial behaviours that can influence the damage done 


\section{Avoiding reputation damage in financial restatements (continued)}

by Fred H. M. Gertsen, Cees B. M. van Riel and Guido Berens

by a restatement," says Van Riel. Part of the initial problem, he explains, was that onlookers making judgements often did not discriminate sufficiently between different levels of financial restatement and their implications. "The first thing we did was to look at what categories of financial restatements actually exist, and what distinctions could be made between them.

"We came up with four types, based on two important criteria. Firstly the degrees to which people perceive distortion, ie, what is the potential impact of the financial restatement on the organisation's future performance. Secondly, the perceived degree of malicious intent. Are the management knowingly and purposely supplying distorted financial figures for their own gain?" with enormous financial implications and a clear and corrupt intent. In between we had two other categories: 'grey accounting hocus-pocus' (low on malicious intent but high on distortion) and 'purple delusion' (low on distortion but high on malicious intent)."

To cover all four categories, they examined financial restatements in 14 companies, both US and European. The restatements occurred in different industries, countries and periods, but all had featured prominently in the international financial press. Wellknown North American names included Goodyear, Nortel, Cablevision and the Federal Home Loan Mortgage Corporate (the US's largest mortgage provider, known as Freddie Mac, which hit the headlines again in the summer of 2008). The four European firms

\section{"Company executives rounding on one another} or shifting the blame leaves analysts questioning whether corporate governance is still in control."

\author{
Many financial restatements fall into \\ the category the team dubbed 'white \\ lies': little distortion and little or no \\ malicious intent, perhaps stemming \\ from human accounting errors. "At \\ worst, we had what we called 'black \\ magic fraud': grave cases, like Enron,
}

included were Shell, Ahold, Adecco and the Italian food company Parmalat.

By studying a wealth of company annual reports, corporate websites, official press releases as well as external press coverage and transcripts of all the analyst question sessions, Van
Riel and colleagues were able to track just how the companies both communicated with the outside world - and responded to the surrounding speculation and enquiries - through the whole period of each financial restatement crisis.

\section{The managerial challenges}

This detailed analysis revealed some key managerial issues arising from financial restatement. None are necessarily disastrous in themselves but they are difficult to manage as they often occur in combination, intensifying the pressure.

The very fact of being investigated, whether by the Justice Department or other regulatory bodies, casts suspicion on, and potentially discredits, senior management who are often already implicated. As companies take remedial action, heads start to roll. When new management arrives, actions and decisions from the past are subject to minute scrutiny and hindsight also comes into play - further discrediting the judgement of past managers.

In what the team called the 'tip-ofthe-iceberg effect', a complete loss of confidence can be triggered by a detail of negligible financial import. The spotlight then turns on the company's other accounting and disclosure practices, perhaps revealing further 
irregularities and errors - and hitting market value once again. "What the organisation tends to do first is to ask for new external accountants," says Van Riel. "They look not only at the specific elements where the financial restatement is focused, but do the whole thing again. And they come in with a totally different mindset from the original 'house' external accountants. They really dig deep and want to find dirt."

The need for financial restatement can also lead to paralysis in corporate communications. Perhaps through fear or lack of experience, some companies instinctively adopt a defensive communication strategy, or worse still, fail to communicate altogether.

Comprehension gaps are also evident, particularly a failure to appreciate internally how the market and analysts will interpret and respond to company statements. Clear distinctions were necessary between restatements required because of accounting 'irregularities' - implying intent - and those resulting from simpler human accounting 'errors', yet observers without professional accounting training (as is generally true within the market) cannot distinguish sufficiently between the two. From the company's standpoint, differentiating between 'good' and 'bad' restatement situations in a nuanced way that will allow outsiders to assess accurately the severity of the situation requires considerable force of argument and the right accounting rhetoric - and management's capacity to do this well and at the appropriate time is critical.

Communication can also be hampered by mixed messages going out when the management, auditors and other gatekeepers are not 'aligned' - that is, where they have not reached a common view on how to handle the situation and especially how/what to communicate to the outside world.

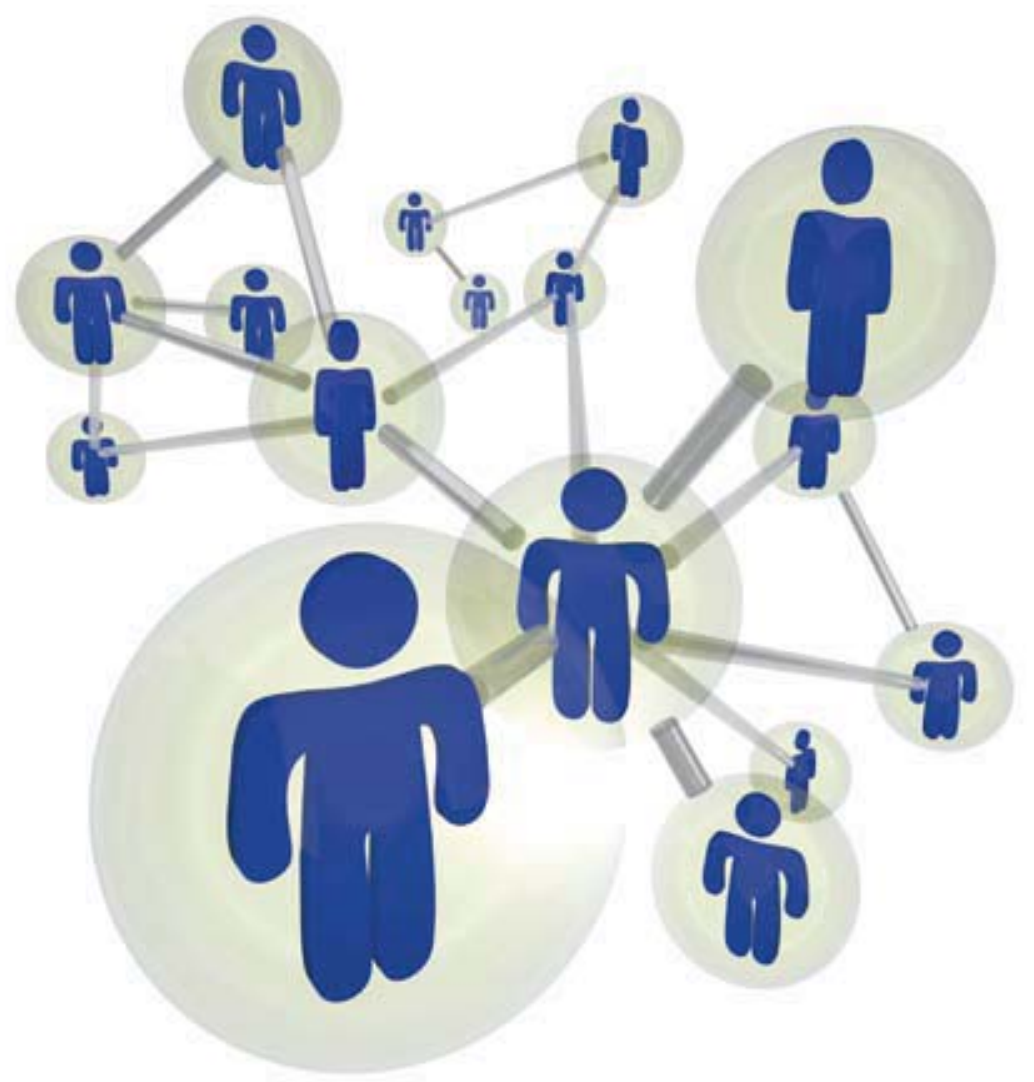

- 'White Lies'
The research team identified four distinctions between categories

of financial restatement and labelled them:

- 'Black Magic Fraud'

- 'Grey Accounting Hocus-pocus'

- 'Purple Delusion' 


\section{Avoiding reputation damage in financial restatements (continued)}

by Fred H. M. Gertsen, Cees B. M. van Riel and Guido Berens

\section{Top tips for managing financial restatements}

So how can companies limit the damage? Addressing five key things can help, says Van Riel. These were areas where differences can really show - where they are handled well (as in the case of Freddie Mac), the benefits are very clearly apparent.

\section{- Confirm the nature of the problem}

Giving statements that confirm the nature of the problem and volunteering explanations to analysts or the media noticeably improves the understanding of these stakeholders. That is critical in limiting distortion, because where there is insufficient understanding negative speculation can circulate. "This fits with what we know from research about consumer inferencemaking," says Van Riel, "namely that people tend to lower their evaluation of a product when they have insufficient information about it."

But, he adds, the research also showed that in these situations executives tend to answer questions in a relatively straightforward way. "Few saw questions as an opportunity to explain issues raised in greater detail or used a question as an opening to persuade the markets that correct strategic decisions have been taken."

\section{- Take the blame}

Company executives rounding on one another or shifting the blame from the company to third parties leaves analysts questioning whether corporate governance is still in control. This can make the situation seem worse, and can also be damaging to executives' perceived trustworthiness. Rarely did companies assume the blame directly for the underlying problems understandable, as this might leave them more open to litigation.

But, as other research has suggested, blame-taking is essential in restoring trust: "When managers avoid blame for something that is clearly their responsibility, this is likely to erode public trust even further. If accepting the blame helps to restore trust where 'honest' mistakes are concerned, does this necessarily hold good where lapses of ethics are concerned, where malicious intent is clearly involved?" This is a difficult area, concedes Van Riel, as the research evidence from elsewhere suggests not.

\section{- Communicate openly}

Open communication is important, right from the outset. The scope of disclosure, ie, how much the company does or does not say, is critical because investors and others in the market will regard it as a proxy for the seriousness of the accounting issues. Providing more details leads them to assume the problems are less widespread, and so again decreases the perceived level of distortion.

Being upfront about how the restatement may affect business operations or financing is seen as a 'constructive factor' in the dialogue between companies and analysts. Most of the companies studied, however, gave general statements, intended to reassure, rather than precise details.

"The cases we analysed provide evidence that precise command of accounting language as a quality of financial leadership has been dismissed in favour of 'governance credos' and sound business performance litany."

Another key mismatch is that while markets expect chief executives to explain technical details and demonstrate their grasp of technical accounting issues, CEOs fight shy of this, leaving such discussions to their chief financial officers. "It was one of the most striking findings," says Van Riel, and "also one of the most difficult to address. It's very hard to say to people at the top of the organisation, your knowledge of finance is just too limited. How do you handle that? How do you tell a CEO that he doesn't understand enough of the financial elements?"

Yet, the researchers argue, with systems now requiring greater scrutiny 
of procedures and wider public access to information, the need for a detailed awareness of financial procedures has intensified. Both CFO and CEO must bear responsibility for financial sign-off to regulators. Insufficient technical knowledge of accounting will no longer be acceptable in mitigation of any reporting irregularities.

\section{- Take corporate governance measures}

Demonstrating not only your commitment to corporate governance but also your ability to take appropriate measures is vital. Where companies do this, stock and bond prices improve accordingly, because those measures lessen fears that the company will act with malicious intent in future.

Wherever fraud or intent was suspected, boards and CEOs took great pains to assure analysts and the media that appropriate action had been taken. "In some cases we saw how remedial actions - often those which were regulatory - had been taken under time pressure. Members of senior management were sacrificed for the cause, but without any public justification of what that cause actually was," says Van Riel.

As a result, some companies scored relatively highly on governance actions but far less well on communicating openly about the problem.

\section{- Act in compliance with the rules}

The cases showed that adhering closely to policies and regulations after the need for a restatement helps to rebuild trust, presumably because the market again becomes more confident that there will not be further instances of malicious intent.

Van Riel is adamant that while financial restatements will still be tough to weather, taking the right attitude from the start can make an enormous difference. "Stubborn behaviour is really not helpful," he says. "What we have seen is that the way to solve a
Cees van Riel is Professor of Corporate Communication, Department of Business-Society Management at Rotterdam School of Management, Erasmus University, and Director of the Corporate Communication Centre.

Fred H. M. Gertsen, PhD, is a Partner with PricewaterhouseCoopers in the Netherlands.

Guido Berens is Assistant Professor of Corporate Branding, Department of Business-Society Management, Rotterdam School of Management, Erasmus University.

\section{"Demonstrating not only your commitment to corporate governance but also your ability to take appropriate measures is vital."}

problem like this is first and foremost to be open from the beginning. Taking the blame because you were responsible, and that's your role. You have to show that you really are being responsible; that you care about the corporate governance measures, and that you are truly acting in compliance with these regulations. Those who did this - as Freddie Mac did - really benefited."
'Avoiding Reputation Damage in Financial Restatements' by Fred H. M. Gertsen, Cees B. M. van Riel and Guido Berens was published in Long Range Planning, Vol. 39, No. 4, August 2006.

The full article is available online at www.sciencedirect.com and on the website of the Reputation Institute: www.reputationinstitute.com/knowledgecenter/articles 